\title{
Using the Dynamic Appraisal of Situational Aggression with mental health inpatients: a feasibility study
}

This article was published in the following Dove Press journal:

Patient Preference and Adherence

28 April 2016

Number of times this article has been viewed

\author{
Tella Lantta' \\ Raija Kontio ${ }^{1-3}$ \\ Michael Daffern ${ }^{4}$ \\ Clive E Adams ${ }^{5}$ \\ Maritta Välimäki 1,6,7 \\ 'Department of Nursing Science, \\ University of Turku, Turku, Finland; \\ ${ }^{2}$ Helsinki University, Helsinki, Finland; \\ ${ }^{3}$ Helsinki University Hospital, \\ Hospital District of Helsinki and \\ Uusimaa, Helsinki, Finland; ${ }^{4}$ Centre for \\ Forensic Behavioural Science (CFBS), \\ Swinburne University of Technology, \\ Melbourne, VIC, Australia; ${ }^{5}$ Institute \\ of Mental Health, University of \\ Nottingham, Nottingham, UK; ${ }^{6}$ Turku \\ University Hospital, Turku, Finland; \\ ${ }^{7}$ School of Nursing, The Hong Kong \\ Polytechnic University, Hong Kong
}

Correspondence: Tella Lantta Department of Nursing Science, University of Turku, Fl-200I4 Turku, Finland

Tel +35823338492

Email tejela@utu.fi
Purpose: This paper aims to explore the acceptability of Dynamic Appraisal of Situational Aggression (DASA) from the perspective of patients, its actual use by mental health nurses, and the predictive validity of the DASA instrument.

Methods: A feasibility study design incorporating quantitative and qualitative components was used. The study was conducted in three mental health inpatient units at three hospitals in southern Finland. Quantitative data were used to explore demand (nurses' actual use of the DASA), limited efficacy (predictive validity), and acceptability (measured through patients' participation in the project). Qualitative data were collected to enhance the understanding of acceptability by describing patients' perceptions of the strengths and weaknesses of the DASA.

Results: Nurses used the DASA for most patient assessments. The predictive validity of the DASA was outstanding or excellent, depending on the type of aggression predicted, although the patient recruitment ratio was low. Patients reported both strengths and weaknesses of the DASA, providing complementary information regarding the instrument's acceptability and clinical application.

Conclusion: The DASA accurately predicts inpatient aggression. The patients' preferences and concerns regarding risk assessment have been noted. More patient involvement in risk assessment research and violence prevention efforts is required.

Keywords: patient participation, nurses, violence, risk assessment, psychiatric hospitals, multi-method approach

\section{Introduction}

Violence carried out by consumers of health care services is a global and widely recognized hazard for staff ${ }^{1-3}$ as well as for fellow patients. ${ }^{4,5}$ Violence in mental health facilities is particularly common and has profound consequences. ${ }^{2}$ Various interventions are used to prevent and manage violence in these settings, including restrictions on consumer/patient movement (eg, physical interventions ${ }^{6}$ ), de-escalation, ${ }^{7}$ recovery planning, ${ }^{8}$ improved collaboration between patients and nurses, ${ }^{9}$ developing organizational culture, ${ }^{10}$ and education to improve staff management of distressed and disturbed patients. ${ }^{11}$

Risk assessment is critical to violence prevention efforts. Treatment guidelines encourage the use of violence risk assessment instruments, ${ }^{12-14}$ such as the Brøset Violence Checklist $\left(\mathrm{BVC}^{15}\right)$ and the Dynamic Appraisal of Situational Aggression $\left(\mathrm{DASA}^{16}\right) .{ }^{14}$ The purpose of these instruments is to aid health care professionals in identifying patients with an increased risk of violence, in order to enable focused preventative interventions. ${ }^{17}$ The frequency of violent incidents ${ }^{18,19}$ and the length of patient seclusion episodes ${ }^{19}$ have been shown to decrease as a result of the systematic 
use of structured violence risk assessments, although the extant research evidence on which these claims are based is small. Only few violence risk assessment studies have considered patients' perceptions of violence risk assessment and management, even though their involvement is emphasized in national guidelines. ${ }^{14,20,21}$ Previous research has shown that patients' own perceptions of their risk of behaving violently could be even more accurate than that of professionals, highlighting the potential usefulness of patients' views in riskrelated decision making. ${ }^{22,23}$ However, a systematic review has revealed that empirical research on patients' involvement in risk assessment and management is scarce, with the available research focusing almost exclusively on predictive accuracy rather than the experiences of patients. ${ }^{24}$

This paper describes a critical exploration of the feasibility of a violence risk assessment instrument, the DASA. ${ }^{16}$ Previous research examining the DASA has focused on its predictive validity, ${ }^{25,26}$ in circumstances when the informed consent of patients has not been required; in these studies, the instrument was neither introduced to patients nor assessments shared with them. To be able to determine whether or not patient involvement in this type of research confers advantage and if modifications for study methods are needed for largescale research projects, ${ }^{27}$ including patients' perspectives on the DASA was deemed important. In the current study, feasibility was evaluated by focusing on three areas as described by Bowen et al: ${ }^{27}$ (1) examining the actual uptake and use of the DASA instrument by staff, (2) exploring the predictive validity of the DASA, and (3) studying the acceptability of the DASA by ascertaining patient's preparedness to take part in this DASA study. Further, patients' perceptions of the strengths and weaknesses of the DASA were elucidated. These aspects are important because many studies reporting the use of structured violence assessment instruments are conducted for research purposes. ${ }^{16,25,26}$ Acceptability of these instruments by patients, as well as descriptions of their usage, particularly the BVC and DASA, in routine care is rare.

\section{Materials and methods}

\section{Aims}

The aims of this feasibility study were to explore demand, limited efficacy (predictive validity), and acceptability of the DASA from the perspective of patients.

\section{Design}

In this study, a feasibility study design, ${ }^{27}$ with a multi-method approach, ${ }^{28}$ was used. We aimed to reach a broad understanding of the feasibility of the DASA, and therefore, both quantitative and qualitative data were gathered. ${ }^{29}$ The study was primarily quantitative with a qualitative component: quantitative data were used to explore demand (nurses' actual use of the DASA), limited efficacy (predictive validity of the DASA), and acceptability (patient recruitment ratio), while qualitative data were collected to complement our understanding of the DASA's acceptability by describing patients' perceptions of the strengths and weaknesses of the DASA. A multi-method approach has been used previously when investigating both the predictive validity of the DASA and nurses' views on the usefulness of the instrument in their practice. ${ }^{30}$ Triangulation of data has been found valuable when comparing findings from different perspectives, preventing possible limitations caused by using a single statistical method. ${ }^{28}$ The study is part of a larger Finnish project "Safer Working Management" (111298), which aims to develop and test new methods to prevent violence, and care for patients at risk of violence in mental health units.

\section{Participants}

This study was conducted in three mental health inpatient units at three hospitals located in one hospital district in southern Finland. The hospital district had 30 adult inpatient units, and all of these were invited to participate in the larger project. Altogether, 20 units volunteered to take part, and a purposive sampling method was further used to select three units out of the total 20. The three units were selected due to their frequent use of coercive measures (manual restraints, seclusion) and a high prevalence of violent incidents, and because no other development projects were being carried out in these units at the time this study began. The units were all locked; one was an acute admission unit (Unit A, 12 beds), one unit specialized in dangerousness assessments (Unit B, 16 beds), and one was a forensic treatment unit (Unit $\mathrm{C}$, 18 beds). The most common psychiatric diagnosis (using the ICD-10) of patients across the three units was "schizophrenic disorder" (42\%-64\%). ${ }^{31}$

Recruitment for this study began on August 14, 2013 and ended on October 10, 2013. Qualified nursing staff were recruited through information meetings run by the researchers (TL, RK, MV) or unit managers of the study units. All registered or enrolled mental health nurses $(n=64)$ working in the three study units and participating in direct patient care were participants; participation was part of their normal working duties. Nurse managers, nursing students, and other health care professionals were excluded.

All the patients $(\mathrm{N}=72)$ who were treated on the units during the DASA instrument use period (September 1-30, 2013) were invited to participate in the study (quantitative component). So, although the DASA was used routinely 
on the units during this period, only data from DASA assessments completed by consenting patients were used in the data analysis. Further, all the patients treated in the study units were eligible to participate in group meetings with researchers and anonymously share their perceptions of the DASA (the qualitative component). Since this was a proof-of-concept study aimed at assessing feasibility, a sample size calculation was not conducted. ${ }^{32}$

Patients' capacity to participate was evaluated based on clinical assessment by the nursing staff and/or the researchers (TL, RK, MV). In practice, this was done by evaluating whether a patient was able to understand what kind of information would be collected from him/her and for what purposes. Thus, the inclusion criteria required that a patient volunteered to participate and was able to provide written informed consent. Patients who refused to participate or those not able to understand the meaning of participations in this study were excluded.

\section{Data collection}

\section{Instrument}

This study focused on the feasibility of patient violence risk assessment in mental health units, performed by nurses using the DASA, and how patients with serious mental health problems perceive this risk assessment instrument and its risk assessment process. The DASA was developed to assist in short-term assessment (next 24 hours) of risk for imminent violence in mental health units. ${ }^{16}$ It is regarded as simple and quick (1-5 minutes per assessment), to be used in day-to-day clinical practice. ${ }^{26,33}$ The DASA comprises seven items: negative attitudes, impulsivity, irritability, verbal threats, sensitivity to perceived provocation, easily angered when requests are denied, and unwillingness to follow directions. ${ }^{16}$ Each of the items (behavioral forms) is scored for its presence or absence in the 24 hours prior to assessment. ${ }^{16}$ A final risk judgment (low, medium, high) is formed based on a review of the items and the total score as well as knowledge of the patient's usual behavior and history of violence. ${ }^{16}$ The DASA has been validated in various clinical settings, ${ }^{26,34,35}$ both in Asia ${ }^{36}$ and in Western countries. ${ }^{30,33}$ It has repeatedly exhibited good-to-excellent predictive accuracy for aggression, ${ }^{25,26,36}$ with good internal consistency and interrater reliability. ${ }^{36}$ The user manual is available from the developers (James RP Ogloff and Michael Daffern).

\section{Implementation}

The knowledge translation strategies formed by the Ottawa Model of Research Use ${ }^{37}$ were used to ensure smooth and managed implementation of the DASA. Neither the staff nor the patients were familiar with the instrument beforehand. Prior to data collection, nurses attended a 2-hour training workshop regarding the rationale for using structured shortterm violence risk assessment in patient care, how to use the DASA and how to involve patients in the DASA assessment process, and the nature of the patient recruitment process. A two-page written description of the DASA (produced by developers) was offered in Finnish; it included detailed instruction about the DASA items and their scoring. Each study unit was also visited regularly to offer hands-on support to staff members and to respond to nurses' questions about the DASA scoring procedure and the interpretation of DASA assessments. Researchers monitored the data collection regularly and were also available by telephone to answer questions regarding the use of the DASA. A more detailed description of the implementation process and instrument translation into Finnish is published elsewhere. ${ }^{38}$

\section{Threefold data collection \\ Demand}

During a 1-month period (September 1-30, 2013), nurses were instructed to complete the DASA form daily. The DASA was completed by each patient's primary nurse at the completion of the morning shift, at around $1 \mathrm{pm}$. Based on this assessment, nurses made a judgment regarding the patients' risk of aggressive behavior, classified as low, moderate, or high. Further, nurses were instructed to discuss their DASA assessment with the patients. Additionally, nurses reported patient aggression against other people (physical or verbal) or objects, perpetrated during the previous 24 hours. To evaluate the actual use of the DASA instrument, a researcher (TL) collected all DASA forms completed during the 1-month period.

\section{Limited efficacy}

Predictive validity was assessed based on DASA forms completed by the nurses and by matching predictions with outcomes (whether the patient was aggressive or violent during the subsequent 24 hours).

\section{Acceptability}

Data for the evaluation of acceptability were based on the patient recruitment ratio, that is, the ratio of eligible patients in the units during the study to those who volunteered to participate. A researcher (TL) collected volunteer patients' DASA assessments, their written informed consent, and information on the total number of patients treated, from the study units. To assess the acceptability of the DASA and its perceived strengths and weaknesses, group meetings (three 
per unit) with semi-structured interviews were organized for the patients. Researchers (one to three in each meeting; TL, RK, MV) led the conversation and wrote notes in the meetings. Prior to the study, patients were given the opportunity to see the DASA instrument form; the items were explained, and the use of the instrument was described. Preliminary perceptions of the DASA were then collected. During the study, patients discussed the challenges and advantages of the DASA with the researchers. After the study, patients were given an opportunity to share their perceptions of the DASA and violence risk assessment in general, orally and/or in written feedback form, whichever they preferred.

Researchers (TL, RK, MV) and nursing staff working in the units recruited patients after providing them with oral and written information regarding the study. ${ }^{39}$ The nursing staff were primarily responsible for recruiting the patients, and they were given written educational material and were supported by the researchers to promote their recruitment efforts. ${ }^{40}$ The researchers requested that every eligible patient should be approached when deemed well enough, ${ }^{41,42}$ by his or her own primary nurse. Patients were informed orally and in written format about the aims and methods of the study, the DASA and violence risk assessment in general, and the time period of the study. Additional general discussion sessions concerning the study were organized for patients, since it has been shown that this may improve attitudes toward the study and increase participation..$^{40,43}$ The voluntary nature of participation and the possibility of discontinuing participation were underlined, and also that neither participation nor refusal would affect the treatment. ${ }^{39}$ To ensure participants' privacy, their demographic information was not collected. In addition, patients were informed that the DASA assessment done by the nurses was a routine part of their treatment during the study, but that written informed consent was required for using their DASA assessments for research purposes.

A more detailed description of the data collection is described in Table 1.

\section{Ethical considerations}

The study plan was approved by the Ethical Committee of the Hospital District of Helsinki and Uusimaa ([HUS] $\S 165 / 29.8 .2012)$. Permission to conduct the study was granted by the directors of the hospital regions (HUS, Helsinki University Central Hospital, §13/30.8.2013; HUS, Hyvinkää Hospital Region, §95/16.8.2013).

\section{Data analysis}

Criteria for assessing feasibility in this study were set as follows:

Table I Threefold data collection

\begin{tabular}{|c|c|}
\hline Data collection & Participants (in total/3 units) \\
\hline \multicolumn{2}{|l|}{ Demand: actual use of DASA instrument } \\
\hline \multicolumn{2}{|l|}{ Prior to the study } \\
\hline Back-translation of instrument & $\mathrm{N} / \mathrm{A}$ \\
\hline Training of the nursing staff & $\mathrm{N} / \mathrm{A}$ \\
\hline \multicolumn{2}{|l|}{ During the study } \\
\hline Daily completion of DASA assessments & $\mathrm{N} / \mathrm{A}$ \\
\hline \multicolumn{2}{|l|}{ After the study } \\
\hline Information about patients' treatment days during the study, and realized & DASA assessments (treatment days), potential amount $(n=I,|1| 6)$ \\
\hline amount of assessments & DASA assessments, realized amount $(n=7 \mid 6)$ \\
\hline \multicolumn{2}{|c|}{ Acceptability: patient recruitment ratio; limited efficacy: predictive validity } \\
\hline \multicolumn{2}{|l|}{ During the study } \\
\hline \multirow[t]{2}{*}{ Daily DASA assessments } & Risk assessments in total $(\mathrm{n}=178)$ \\
\hline & Patients with informed consent $(n=12)$ \\
\hline \multicolumn{2}{|c|}{ Acceptability: patients' perceptions of strengths and weaknesses of DASA use } \\
\hline \multicolumn{2}{|l|}{ Meeting prior to the study } \\
\hline Introduction of the DASA & Patients $(n=27)$ \\
\hline \multicolumn{2}{|l|}{ Procedure of instrument use during the study } \\
\hline \multicolumn{2}{|l|}{ Preliminary perceptions of the DASA } \\
\hline \multicolumn{2}{|l|}{ Meeting during the study } \\
\hline Strengths and weaknesses of DASA use & Patients $(n=26)$ \\
\hline \multicolumn{2}{|l|}{ Meeting after the study } \\
\hline \multirow[t]{2}{*}{ Strengths and weaknesses of DASA use } & Patients $(n=19)$ \\
\hline & Written feedback $(n=5)$ \\
\hline
\end{tabular}

Abbreviations: DASA, Dynamic Appraisal of Situational Aggression; N/A, not applicable. 
- Demand: at least $65.6 \%$ of possible DASA assessments are completed

- Limited efficacy: predictive validity is $\geq 0.70$

- Acceptability: patient recruitment ratio is at least $51.2 \%$

- Acceptability: collecting patients' perceptions regarding the strengths and weaknesses of the DASA can be realized.

First, the criterion for demand by outcome of nursing staff's actual use of the instrument is a mean percentage (65.6\%) from three independent studies: (1) Griffith et $\mathrm{al}^{26}$ reported that $64.6 \%$ of nurses consented to participate in a DASA predictive validity study. (2) Hvidhjelm et $\mathrm{al}^{44}$ reported that realized assessment of aggressive incidents in mental health inpatient settings by using Staff Observation Aggression Scale-Revised $(\mathrm{SOAS}-\mathrm{R})^{45}$ instrument was $55 \%$. (3) Berry et $\mathrm{al}^{46}$ reported that $77.27 \%$ of staff were willing to take part in ward-based psychological intervention study in mental health inpatient setting. Second, the criterion for limited efficacy by outcome of predictive validity is set for area under the curve (AUC) values $\geq 0.70 .^{47,48}$ A third measure of acceptability is derived from the average recruitment ratio, 51.2\% (range: 4.3\%-95.4\%), reported in a systematic review by Trivedi et al. ${ }^{49}$

The analysis of the various datasets proceeded as follows.

\section{Demand}

Determination of demand was ascertained by first calculating the total number of possible DASA assessments conducted in the three units over the course of the study period (the total number of patients' treatment days; one treatment day allows for one possible completed DASA assessment). The actual number of DASA assessments conducted was then divided by the number of possible assessments, and presented as a percentage.

\section{Limited efficacy (predictive validity)}

Data concerning the DASA's predictive validity were evaluated by calculating the receiver operating characteristic and the AUC values, executed by analyzing the results of both DASA total scores and the nurses' judgment on the final risk rating and recorded aggression incidents (included in the DASA form) in the following 24 hours. ${ }^{50}$ In this receiver operating characteristic analysis, it was assumed that each DASA result was an independent unit of data. ${ }^{36}$ AUC values between 0.70 and 0.79 were seen as acceptable, values between 0.80 and 0.89 were considered to be excellent, and values over 0.9 were outstanding. ${ }^{47}$ The occurrence of violence during the study was analyzed with descriptive statistics (percentages). The data were analyzed using IBM SPSS Statistics for Windows, Version 21.0. (IBM Corp., Armonk, NY, USA).

\section{Acceptability}

Data concerning the acceptability of the DASA were analyzed in two ways. The ratio of patients who were recruited into the study compared to the total number of patients admitted to the three units was calculated and reported as a percentage. Patients' perceptions concerning the strengths and weaknesses of the use of the DASA and violence risk assessment in general were analyzed in Finnish, using directed qualitative content analysis, ${ }^{51}$ coding the feedback as strengths or weaknesses. This analysis method was chosen because we wanted to focus the analysis on the feasibility aspect of "acceptability", and directed coding was deemed appropriate for seeking to answer this question. First, the notes that the researchers took in group meetings (semi-structured interviews) and patients' written feedback were combined to form a single Word document. Second, by reading these perceptions carefully, an overall picture was formed from the text. Third, the predetermined codes "strength" and "weakness" were kept in mind as the text was reread. Words or phrases were highlighted at the same time in two different colors. Fourth, highlighted codes were transferred to a separate Word document. Fifth, all highlighted words or phrases were grouped into categories based on how they were related. For example, the category of "increased communicativeness" included the phrases "Openness in treatment has increased", "Awareness has increased", and "I have reflected on the topic with the nurses".

\section{Rigor}

In previous research, the predictive validity of the DASA has been established in general mental health inpatients units $^{26,30}$ and in forensic mental health units. ${ }^{25,33}$ The credibility of the qualitative data was established by collecting patients' perceptions from three different units, at three different times: a range of ages and both sexes were represented to gain rich variation of the phenomena under study. The credibility of research findings was supplemented by combining coding among co-researchers (TL, MV, RK), who were present in data collection. Together, the researchers came to an agreement about the categories into which the data would be classified. A clear and detailed description of the analysis process and the coding system used strengthens the credibility and transparency of the data analysis. Further, by giving examples of original excerpts of patient interviews 
in the results of the analysis, we have sought to maintain the patients' own words. Using the same researchers during different points of data collection, who took notes during the meetings and transcribed the notes immediately after meetings, is seen to have contributed to the dependability of this study. An open dialogue between researchers, nursing staff, and patients during the entire data collection process aimed to ensure consistency of the data collection over time. The setting of the study, the participants, and the methods used are described in the present article in as much detail as possible, to add transferability of the findings. ${ }^{52}$

\section{Results}

\section{Demand}

\section{Realized use}

During the period of the data collection, 72 patients were treated in the units. If patients had been assessed daily during their treatment period, we would have had 1,116 completed DASA assessments. Nurses completed 716 assessments (64\%) on a total of 52 patients ( $72 \%$ of all possible patients). Between the three units, the realization rate varied between $14.7 \%$ and $88.5 \%$ (Table 2).

\section{Limited efficacy \\ Predictive validity}

In total, 178 risk assessments for 12 consenting patients were completed. DASA assessments showed a skewed distribution. In most cases, patients were assessed as " 0 " $(n=146,82.0 \%)$ (Figure 1). During the study period, physical aggression against others was reported three times for one patient ( $1.7 \%$ of the sample), and verbal aggression against others five times for two patients (2.8\% of the sample). Aggression against objects was not reported by patients.

AUC as an indicator of predictive validity of DASA total scores ranged from 0.84 (verbal aggression against others) to 0.93 (physical aggression against others). AUC values for nurses' final risk rating (low, moderate, and high) were 0.75 (verbal aggression against others) and 0.78 (physical aggression against others) (Table 3).

\section{Acceptability}

\section{Recruitment ratio}

Of 72 patients, 12 gave informed consent to use their risk assessment data (17\%). The patient recruitment rates in participating units were 4.3\% (Unit A), 23.8\% (Unit C), and 100\% (Unit B).

\section{Strengths and weaknesses of DASA instrument use}

In total, 72 patients participated in semi-structured interviews in three units, on three different occasions (a total of nine organized group meetings with the patients). To ensure the privacy of participants, and a trusting relationship with the researchers, patients' demographic data were not gathered. A low threshold for meeting participation was seen as essential for collecting qualitative data for this feasibility study.

The patients identified many strengths in DASA instrument use in each participating unit, including increased communicativeness, increased patient understanding that violence risk assessment was part of routine nursing activity, and patients were interested in the DASA and were positive about introducing the instrument to their unit. In general, patients were aware of the DASA; they understood the scoring and discussed this scoring with each other, for example, "Today I scored a zero!". Patients and nurses together evaluated, for example, what had happened during the week, which led to higher DASA scores than zero. Patients noted that they had discussed the topic of violence risk with nurses, which suggests that conversations related to the results of DASA assessments and the early warning signs of violence in general were communicated. Patients reported trusting in the structured assessment methods and wanted to know how the instrument was developed. In addition, they were satisfied that patients were assessed equally, not based on nurses' opinions and perceived biases.

Weaknesses were also identified in each participating unit, and described in five ways. First, patients complained that assessment only focused on negative things. Patients would like to have the possibility to develop the DASA instrument further, and add items which measure positive aspects of one's

Table 2 Use of DASA in study units

\begin{tabular}{llll}
\hline Unit & $\begin{array}{l}\text { DASA assessments (treatment days), } \\
\text { potential amount }\end{array}$ & $\begin{array}{l}\text { Amount of realized DASA assessments } \\
\text { (\% out of potential amount) }\end{array}$ & $\begin{array}{l}\text { DASA assessments } \\
\text { (\% out of realized amount) }\end{array}$ \\
\hline Unit A & 315 & $208(66.0 \%)$ & $11(5.3 \%)$ \\
Unit B & 270 & $38(14.7 \%)$ & $38(100 \%)$ \\
Unit C & 531 & $470(88.5 \%)$ & $129(27.4 \%)$ \\
Total & 1,116 & $716(64.2 \%)$ & $178(24.9 \%)$ \\
\hline
\end{tabular}

Abbreviation: DASA, Dynamic Appraisal of Situational Aggression. 


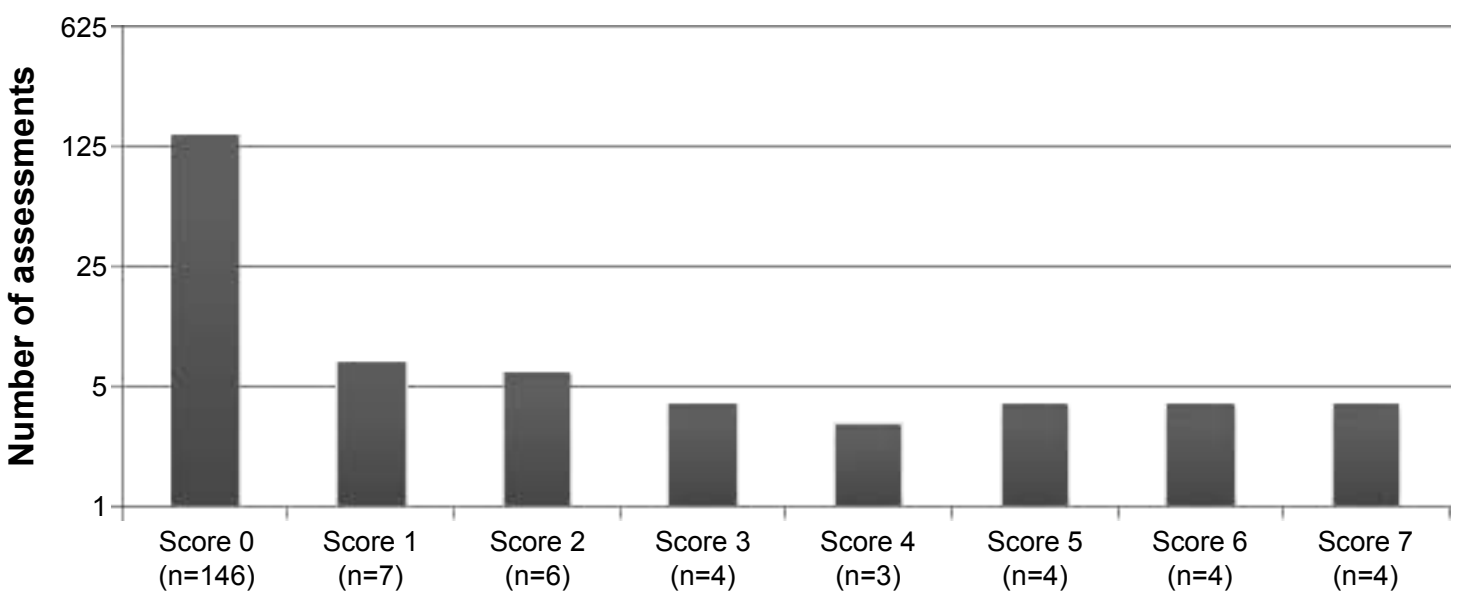

Figure I Dynamic Appraisal of Situational Aggression assessment scores during I-month study.

behavior. They also argued that they could not assess nurses, respectively. Second, patients were upset about scoring in general, and did not see it as respectful of the patient. They considered assessing people from " 0 " to " 1 " to be insulting. Some felt the use of the DASA to be degrading: "We are not test animals". Third, patients described concerns regarding the objectivity of the assessment: they worried that nurses' negative attitudes toward them may adversely impact the DASA score, and therefore, lead to consequences, like restrictions on the unit. They also wondered whether items in the DASA (eg, impulsivity) are personal characteristics and whether nurses are able to ascertain the difference between their usual and atypical, possibly violence-related, behavior. Fourth, patients questioned whether the DASA was time-consuming. They were concerned that completion of the DASA would decrease the time that nurses would be present and available in units. Finally, the patients reported that they did not have enough opportunities to see and discuss their DASA assessments with nurses. Furthermore, they lacked information regarding how the assessment affected their own treatment.

\section{Discussion}

The main purpose of our feasibility study was to explore demand, limited efficacy, and acceptability of the DASA from the perspective of patients. We evaluated the real-world use of the DASA, predictive validity, patients' preparedness to participate (as a proxy measure of their interest in the instrument), and their perceptions of the strengths and weaknesses of the DASA. We set feasibility criteria for each outcome, and based on these criteria, we believe there is merit in making recommendations for future violence risk assessment research with patient participation.

Our study showed a difference between researcher-led violence risk assessment studies and instrument use in reallife situations, where nurses implement the instrument in the unit and patient participation is voluntary. In less than twothirds of the treatment days during the study, DASA assessments were completed. In contrast, Griffith et $\mathrm{al}^{26}$ reported that DASA forms were checked for missing information by a researcher, and if necessary, completed retrospectively, based on nursing notes and patient files. With this procedure, only three assessments were left incomplete during a 2-month experimental study period. ${ }^{26}$ However, Dumais et al ${ }^{30}$ also reported that many patients were not assessed using the DASA during their study period. In our study, realization rates of the DASA assessments varied a great deal across participating units $(15 \%-89 \%)$. The lowest realization rate might be partly explained by forthcoming organizational

Table 3 Predictive validity of the DASA

\begin{tabular}{lll}
\hline $\begin{array}{l}\text { Type of aggression occurring during } \\
\text { the next } \mathbf{2 4} \text { hours }\end{array}$ & $\begin{array}{l}\text { DASA total score, } \\
\text { AUC (95\% CI) }\end{array}$ & $\begin{array}{l}\text { Nurses' judgment on final } \\
\text { risk rating, AUC (95\% CI)* }\end{array}$ \\
\hline $\begin{array}{ll}\text { Physical aggression against objects }(n=0) \\
\text { N/A }\end{array}$ & $0.92(0.87-0.97)$ & $0.78(0.46-1.00)$ \\
Physical aggression against others $(n=3)$ & $0.86(0.62-1.00)$ & $0.75(0.49-1.00)$ \\
\hline
\end{tabular}

Note: *Risk of aggression was rated as low, moderate, or high.

Abbreviations: DASA, Dynamic Appraisal of Situational Aggression; AUC, area under the curve; Cl, confidence interval; N/A, not applicable. 
changes in one unit: Unit B was going to close down soon after our study ended. ${ }^{38}$ Thus, staff might have been resistant toward using a new instrument in their daily clinical practice. Resistive ward culture ${ }^{53}$ and perceived lack of organizational support ${ }^{54}$ have been found to be two of the reasons implementation of evidence-based interventions in care is hindered. Previous research indicates additional explanations as to why, in general clinical practice, the DASA may not be completed reliably: first, the demands of the setting might not allow adequate time to conduct assessments; second, staff may not be adequately trained; ${ }^{33}$ third, staff may prefer their own clinical judgment (also including relying heavily on intuition) instead of using a structured assessment method. ${ }^{55}$

Interestingly, regarding the predictive validity of the DASA, our study found that AUC values were lower for nurses' final risk ratings than the DASA total score, which was derived actuarially. This result is consistent with Griffith et al, ${ }^{26}$ where nurses' structured clinical judgment ratings were more accurate than unaided clinical assessments but less accurate than DASA total scores. Both studies suggest that nurses' judgments are less accurate than the actuarially derived score. This finding is particularly relevant to staff training and suggests that caution should be exerted before nurses adjust the DASA-derived score and "override" the risk rating.

The present study also revealed that, when patients were invited to participate in this violence risk assessment research, few (in this study only 17\%) were willing to participate. To the best of our knowledge, this was the first time the DASA results have been shared with patients in an empirical study, and the first time that patients have been invited to comment on the nature of this type of nursing-led activity. Even though the DASA assessment is not invasive, it requires assessment of private information about a patient's risk of violence, and the results may impact staff management involving the patient. According to the World Medical Association's Declaration of Helsinki, ${ }^{56}$ vulnerable populations, such as forensic mental health patients, ${ }^{57}$ specifically need protection. For that reason we argue that, where possible, informed consent should be sought. However, given that many repeatedly violent patients can be disagreeable, informed consent should not be considered mandatory for violence risk assessment research. Otherwise, the most severely violent and high-risk patients, from whom we stand to learn a great deal, may not participate, thereby invalidating the results of the research. Good clinical practice and research indicates that informing patients about issues related to their care is warranted - a moral responsibility for professional staff. ${ }^{58}$ However, for valid research, transparency is required, not only proceeding based on consent to participate. Nevertheless, we stand to learn from patients about their perceptions of risk assessment, and effort should be made to garner their opinions of risk assessment procedures.

Patients' experiences of their involvement in structured risk assessment have rarely been studied. ${ }^{24} \mathrm{Clinical}$ guidelines recommend patient involvement in violence risk assessment and management research. ${ }^{14,20,21}$ When we explored patients' perceptions of the strengths and weaknesses of the DASA, one major theme was their uncertainty as to how the assessment would impact their care and management. They gave useful suggestions to enhance involvement, including adding the measuring of positive aspects in one's behavior, providing an opportunity to discuss assessment results, and also that the experience of assessment should be objective, not simply based on professionals' intuitive evaluations. The willingness of patients to be more involved in their own treatment has been among the previously proposed strategies related to prevention and management of aggression in general. ${ }^{59,60}$ Some positive outcomes have already been reached by, for example, Fluttert et al, ${ }^{9}$ by implementing a more individualized violence risk management method, the "Early Recognition Method", which includes weekly risk assessment, and aims to improve collaboration between patients and nurses. Future research may look to expand patient engagement in violence risk assessment and management tasks, specifically in short-term evaluations using the BVC and DASA.

The possibility of recruiting patients for large violence risk assessment studies whereby informed consent is required presents many challenges. Although the predictive validity of the DASA was excellent or outstanding in this study, the sample was small, and it included only consenting patients. The occurrence of violent incidents during the data collection period was low. Nevertheless, our results are similar to studies that have been conducted irrespective of patient consent. However, we do not know how participants and nonparticipants compared in terms of their DASA scores or violent behavior, so this result must be judged with caution. Examining potential participants' willingness to participate allowed us to identify recruitment problems, ${ }^{61}$ and avoid a possible underpowered, unethical full-scale trial. ${ }^{62} \mathrm{We}$ feel this feasibility study was highly valuable, giving insight to patients' perceptions and preferences, despite its small sample size and brief recruitment period.

\section{Limitations}

Our study has several limitations. First, our patient recruitment ratio was low, which led to a small sample size. 
The main responsibility of recruiting the patients fell on the nursing staff, which may have affected the recruitment process. For example, nurses may have felt that recruitment was extra work for them. The recruitment ratio was notably low $(4.3 \%)$ in the unit, which is an acute admission unit with high patient turnover. We can assume that a hectic work environment might have made patient recruitment a low priority among the daily working duties. Across the units, the nurses were also concerned with whether or not the patients were too ill to make the decision to participate in the study. Nurses said that violent behavior is a difficult topic to discuss with patients. ${ }^{38}$ We may also wonder if the nurses knew how to approach patients to ask for their informed consent, or what would be the most appropriate timing of approach. ${ }^{41,43}$ Thus, although every effort was made to support staff members in the recruitment process, more efficient recruitment and education strategies could have been used, ${ }^{43}$ for example, audio-visual techniques to increase patients' awareness in the informed consent process, ${ }^{40}$ or offering more effective recruitment education for the staff members. ${ }^{43}$

Second, the economics in relation to using the DASA were not investigated as part of our study. However, as noted in the patient interviews, staff time completing the DASA assessment directs time away from other nursing activities; the benefits and costs associated with the use of the DASA require investigation. We focused only on the feasibility of the DASA through demand and acceptability; a cost analysis would be important to conduct as part of large-scale study in the future. We know the DASA is low cost: in our study, training was conducted in 2 hours, each assessment took between 1 and 5 minutes of staff time, daily per patient. Estimated benefits and potential savings, such as a decrease in violent events, seem promising in light of previous randomized control trials for violence risk assessment. ${ }^{18,19}$ Nevertheless, an economic analysis is an often neglected part of violence risk assessment research, ${ }^{63}$ and should be a focus of future research.

Third, generalization of the quantitative findings must be approached with caution. The setting of the study was only one hospital district in a culturally homogeneous, sparsely populated country. In addition, the sample size was relatively small. It can also be questioned if our sample related to predictive accuracy evaluation of the DASA has statistical independence. We, however, did handle the data as each DASA score being an independent unit of data. The results were in line with previous research, regardless of the small sample size and low occurrence of violent incidents.
Fourth, transferability of the qualitative findings is limited to mental health hospital units treating people with severe mental illness. Because of the anonymity guaranteed for participating patients, we were unable to further discuss our interpretations of the qualitative data with participating patients or to control for selection bias, as we do not know who participated and who refused to participate. Understanding the characteristics of those patients who were willing to participate would have strengthened the generalizability of the findings. Last, a broader understanding of the feasibility of the DASA would have been gained by assessing all the aspects of the tool as suggested by Bowen et $\mathrm{al}^{27}$ (eg, practicality, implementation, integration, and adaptation). Indeed, these aspects merit attention and have been discussed as part of the implementation report of the present study. ${ }^{38}$

\section{Conclusion}

This study is the first to include patient participation in an inpatient violence risk assessment study; it highlights patient preferences and concerns. Results reveal the feasibility of the DASA and the potential importance of structured violence risk assessments. However, patient involvement in risk assessment research and violence prevention efforts needs particular attention, and novel methods for this are required. Further, nursing staff may benefit from more education and engagement regarding risk assessment and its potential advantages and limitations in patient care.

When designing large-scale violence risk assessment studies in mental health units, we recommend: (1) increased engagement with patients to learn more about the process of sharing assessment results to enhance care and management in the violence prevention process; (2) more intensive staff training about sharing violence risk assessment results with patients, to increase patient involvement in the use of the DASA and other structured violence risk assessments; (3) patient involvement in recruitment - perhaps by collaboratively designing the recruitment process; (4) where possible, collection of details regarding important demographic characteristics of participants and nonparticipants; and (5) inclusion of a cost-benefit analysis in relation to the use of the DASA.

\section{Acknowledgments}

We wish to thank MSocSc, Senior Planning Officer Pauli Puukka (National Institute for Health and Welfare, Turku, Finland), for his guidance with statistical analyses, and staff members and patients who participated in our study. This work was supported by the Finnish Work Environment 
Fund (grant number 111298), Doctoral Programme in Nursing Science (DPNurs), University of Turku, Finland, Foundations' Professor Pool (the Finnish Cultural Foundation), and the Hospital District of Helsinki and Uusimaa.

\section{Author contributions}

MV, TL, RK, and MD designed the study. TL, RK, and MV collected the data. TL and MV analyzed the data, and all the authors contributed to interpretation of data for the study. TL, $\mathrm{MV}$, and RK drafted the paper, and MD and CEA revised it critically for important intellectual content. All authors read and approved the final manuscript, and agree to be accountable for all aspects of the work.

\section{Disclosure}

MD is one of the developers of the DASA instrument (Ogloff and Daffern, 2006) used in the project described in this article, and reports no other conflicts of interest in this work. TL, RK, CEA, and MV report no conflicts of interest in this work.

\section{References}

1. Flannery RB Jr, LeVitre V, Rego S, Walker AP. Characteristics of staff victims of psychiatric patient assaults: 20-year analysis of the Assaulted Staff Action Program. Psychiatr Q. 2011;82(1):11-21.

2. Spector PE, Zhou ZE, Che XX. Nurse exposure to physical and nonphysical violence, bullying, and sexual harassment: a quantitative review. Int J Nurs Stud. 2014;51(1):72-84.

3. Itzhaki M, Peles-Bortz A, Kostistky H, Barnoy D, Filshtinsky V, Bluvstein I. Exposure of mental health nurses to violence associated with job stress, life satisfaction, staff resilience, and post-traumatic growth. Int J Ment Health Nurs. 2015;24(5):403-412.

4. Foster C, Bowers L, Nijman H. Aggressive behaviour on acute psychiatric wards: prevalence, severity and management. $J$ Adv Nurs. 2007; 58(2):140-149.

5. Uppal G, McMurran M. Recorded incidents in a high-secure hospital: a descriptive analysis. Crim Behav Ment Health. 2009;19(4):265-276.

6. Stubbs B, Leadbetter D, Paterson B, Yorston G, Knight C, Davis S. Physical intervention: a review of the literature on its use, staff and patient views, and the impact of training. J Psychiatr Ment Health Nurs. 2009; 16(1):99-105.

7. Price O, Baker J. Key components of de-escalation techniques: a thematic synthesis. Int J Ment Health Nurs. 2012;21(4):310-319.

8. Goetz SB, Taylor-Trujillo A. A change in culture: violence prevention in an acute behavioral health setting. $J$ Am Psychiatr Nurses Assoc. 2012;18(2):96-103.

9. Fluttert FA, van Meijel B, Nijman H, Bjorkly S, Grypdonck M. Preventing aggressive incidents and seclusions in forensic care by means of the "Early Recognition Method'. J Clin Nurs. 2010;19(11-12):1529-1537.

10. Bowers L, James K, Quirk A, et al. Reducing conflict and containment rates on acute psychiatric wards: The Safewards cluster randomised controlled trial. Int J Nurs Stud. 2015;52(9):1412-1422.

11. Lahti M, Kontio R, Pitkanen A, Valimaki M. Knowledge transfer from an e-learning course to clinical practice. Nurse Educ Today. 2014;34(5): 842-847.

12. American Psychiatric Association. Practice guidelines for the treatment of patients with schizophrenia [cited December 20, 2015]. Available from: http://psychiatryonline.org/pb/assets/raw/sitewide/practice_guidelines/guidelines/schizophrenia.pdf. Accessed January 11, 2016.
13. National Institute for Health and Clinical Excellence. Psychosis and schizophrenia in adults: treatment and management. NICE clinical guideline 178 [updated March 2014; cited November 23, 2015]. Available from: http://www.nice.org.uk/guidance/cg178/resources/ psychosis-and-schizophrenia-in-adults-prevention-and-management35109758952133. Accessed January 11, 2016.

14. National Institute for Health and Care Excellence. Violence and aggression: short-term management in mental health, health and community settings. NICE guideline [NG10] [updated May 28, 2015; cited November 23, 2015]. Available from: https://www.nice.org. uk/guidance/ng10/resources/violence-and-aggression-shorttermmanagement-in-mental-health-health-and-community-settings1837264712389. Accessed January 11, 2016.

15. Almvik R, Woods P. The Brøset Violence Checklist (BVC) and the prediction of in-patient violence: some preliminary results. Psychiatric Care. 1998;1(5):208-211.

16. Ogloff JR, Daffern M. The dynamic appraisal of situational aggression: an instrument to assess risk for imminent aggression in psychiatric inpatients. Behav Sci Law. 2006;24(6):799-813.

17. Allnutt SH, Ogloff JR, Adams J, et al. Managing aggression and violence: the clinician's role in contemporary mental health care. Aust N Z J Psychiatry. 2013;47(8):728-736.

18. Abderhalden C, Needham I, Dassen T, Halfens R, Haug HJ, Fischer JE. Structured risk assessment and violence in acute psychiatric wards: randomised controlled trial. Br J Psychiatry. 2008;193(1):44-50.

19. van de Sande R, Nijman HL, Noorthoorn EO, et al. Aggression and seclusion on acute psychiatric wards: effect of short-term risk assessment. Br J Psychiatry. 2011;199(6):473-478.

20. Government of Western Australia. Guidelines: the management of disturbed/violent behaviour in inpatient psychiatric settings [cited November 23, 2015]. Available from: http://www.health.wa.gov. $\mathrm{au} /$ docreg/Education/Population/Health_Problems/Mental_Illness/ HP8973_The_management_of_disturbed_violent_behaviour.pdf. Accessed January 11, 2016.

21. Department of Health at the United Kingdom 2007. Best practice in managing risk [updated June 2007; cited November 23, 2015]. Available from: http://webarchive.nationalarchives.gov.uk/+/www.dh.gov. uk/prod_consum_dh/groups/dh_digitalassets/@dh/@en/documents/ digitalasset/dh_076512.pdf. Accessed January 11, 2016.

22. Roaldset JO, Bjorkly S. Patients' own statements of their future risk for violent and self-harm behaviour: a prospective inpatient and postdischarge follow-up study in an acute psychiatric unit. Psychiatry Res. 2010;178(1):153-159.

23. Skeem JL, Manchak SM, Lidz CW, Mulvey EP. The utility of patients' self-perceptions of violence risk: consider asking the person who may know best. Psychiatr Serv. 2013;64(5):410-415.

24. Eidhammer G, Fluttert FA, Bjorkly S. User involvement in structured violence risk management within forensic mental health facilities - a systematic literature review. J Clin Nurs. 2014;23(19-20): 2716-2724.

25. Chu CM, Thomas SD, Ogloff JR, Daffern M. The short- to medium-term predictive accuracy of static and dynamic risk assessment measures in a secure forensic hospital. Assessment. 2013;20(2):230-241.

26. Griffith JJ, Daffern M, Godber T. Examination of the predictive validity of the Dynamic Appraisal of Situational Aggression in two mental health units. Int J Ment Health Nurs. 2013;22(6):485-492.

27. Bowen DJ, Kreuter M, Spring B, et al. How we design feasibility studies. Am J Prev Med. 2009;36(5):452-457.

28. Williamson GR. Illustrating triangulation in mixed-methods nursing research. Nurse Res. 2005;12(4):7-18.

29. O'Cathain A, Murphy E, Nicholl J. The quality of mixed methods studies in health services research. J Health Serv Res Policy. 2008;13(2): 92-98.

30. Dumais A, Larue C, Michaud C, Goulet MH. Predictive validity and psychiatric nursing staff's perception of the clinical usefulness of the French version of the Dynamic Appraisal of Situational Aggression. Issues Ment Health Nurs. 2012;33(10):670-675. 
31. World Health Organization. International classification of diseases (ICD) [cited November 23, 2015]. Available from: http://www.who. int/classifications/icd/en/. Accessed January 11, 2016.

32. Thabane L, Ma J, Chu R, et al. A tutorial on pilot studies: the what, why and how. BMC Med Res Methodol. 2010;10:1.

33. Vojt G, Marshall LA, Thomson LDG. The assessment of imminent inpatient aggression: a validation study of the DASA-IV in Scotland. The J Forens Psychiatry Psychol. 2010;21(5):789-800.

34. Barry-Walsh J, Daffern M, Duncan S, Ogloff J. The prediction of imminent aggression in patients with mental illness and/or intellectual disability using the Dynamic Appraisal of Situational Aggression instrument. Australas Psychiatry. 2009;17(6):493-496.

35. Kasinathan J, Marsland C, Batterham P, Gaskin C, Adams J, Daffern M. Assessing the risk of imminent aggression in mentally ill young offenders. Australas Psychiatry. 2015;23(1):44-48.

36. Chan O, Chow KK. Assessment and determinants of aggression in a forensic psychiatric institution in Hong Kong, China. Psychiatry Res. 2014;220(1-2):623-630.

37. Logan J, Graham I. Toward a comprehensive interdisciplinary model of health care research use. Sci Commun. 1998;20(2):227-246.

38. Lantta T, Daffern M, Kontio R, Valimaki M. Implementing the Dynamic Appraisal of Situational Aggression in mental health units. Clin Nurse Spec. 2015;29(4):230-243.

39. Medical Research Act No. 488/1999. Ministry of Social Affairs and Health, Finland. Available from: http://www.finlex.fi/fi/laki/ kaannokset/1999/en19990488.pdf. Accessed April 8, 2016.

40. Caldwell PH, Hamilton S, Tan A, Craig JC. Strategies for increasing recruitment to randomised controlled trials: systematic review. PLoS Med. 2010;7(11):e1000368.

41. Woodall A, Howard L, Morgan C. Barriers to participation in mental health research: findings from the Genetics and Psychosis (GAP) Study. Int Rev Psychiatry. 2011;23(1):31-40.

42. Ennis L, Wykes T. Impact of patient involvement in mental health research: longitudinal study. Br J Psychiatry. 2013;203(5):381-386.

43. Jorgensen R, Munk-Jorgensen P, Lysaker PH, Buck KD, Hansson L, Zoffmann V. Overcoming recruitment barriers revealed high readiness to participate and low dropout rate among people with schizophrenia in a randomized controlled trial testing the effect of a Guided Self-Determination intervention. BMC Psychiatry. 2014;14:28.

44. Hvidhjelm J, Sestoft D, Bjorner JB. The Aggression Observation Short Form identified episodes not reported on the Staff Observation Aggression Scale - Revised. Issues Ment Health Nurs. 2014;35(6):464-469.

45. Nijman HLI, Muris P, Harald LGJ, et al. The Staff Observation Aggression Scale-Revised (SOAS-R). Aggressive Behavior. 1999;25(3): 197-209.

46. Berry K, Haddock G,- Kellett S, Roberts C, Drake R, Barrowclough C. Feasibility of a ward-based psychological intervention to improve staff and patient relationships in psychiatric rehabilitation settings. Br J Clin Psychol. Epub 2015 Apr 17.

47. Hosmer DW Jr, Lemeshow S. Applied Logistic Regression. 2nd ed. New York: Wiley; 2000.
48. Fischer JE, Bachmann LM, Jaeschke R. A readers' guide to the interpretation of diagnostic test properties: clinical example of sepsis. Intensive Care Med. 2003;29(7):1043-1051.

49. Trivedi RB, Szarka JG, Beaver K, et al. Recruitment and retention rates in behavioral trials involving patients and a support person: a systematic review. Contemp Clin Trials. 2013;36(1):307-318.

50. Lewis AHO, Webster CE. General instruments for risk assessment. Curr Opin Psychiatry. 2004;17(5):401-405.

51. Hsieh HF, Shannon SE. Three approaches to qualitative content analysis. Qual Health Res. 2005;15(9):1277-1288.

52. Graneheim UH, Lundman B. Qualitative content analysis in nursing research: concepts, procedures and measures to achieve trustworthiness. Nurse Educ Today. 2004;24(2):105-112.

53. Wells N, Free M, Adams R. Nursing research internship: enhancing evidence-based practice among staff nurses. J Nurs Adm. 2007;37(3): $135-143$.

54. Kajermo KN, Unden M, Gardulf A, et al. Predictors of nurses' perceptions of barriers to research utilization. J Nurs Manag. 2008;16(3): 305-314.

55. Daffern M, Howells K, Hamilton L, Mannion A, Howard R, Lilly M. The impact of structured risk assessments followed by management recommendations on aggression in patients with personality disorder. J Forens Psychiatry Psychol. 2009;20(5):661-679.

56. World Medical Association. WMA Declaration of Helsinki-ethical principles for medical research involving human subjects [updated October 2013; cited November 28, 2015]. Available from: http://www.wma.net/ en/30publications/10policies/b3/. Accessed January 11, 2016.

57. Munthe C, Radovic S, Anckarsater H. Ethical issues in forensic psychiatric research on mentally disordered offenders. Bioethics. 2010; 24(1):35-44.

58. Doyal L. Good clinical practice and informed consent are inseparable. Heart. 2002;87(2):103-106.

59. Kontio R, Joffe G, Putkonen H, et al. Seclusion and restraint in psychiatry: patients' experiences and practical suggestions on how to improve practices and use alternatives. Perspect Psychiatr Care. 2012; 48(1):16-24.

60. Kontio R, Anttila M, Lantta T, Kauppi K, Joffe G, Valimaki M. Toward a safer working environment on psychiatric wards: service users' delayed perspectives of aggression and violence-related situations and development ideas. Perspect Psychiatr Care. 2014;50(4):271-279.

61. Halpern SD, Metzger DS, Berlin JA, Ubel PA. Who will enroll? Predicting participation in a phase II AIDS vaccine trial. J Acquir Immune Defic Syndr. 2001;27(3):281-288.

62. Halpern SD, Karlawish JH, Berlin JA. The continuing unethical conduct of underpowered clinical trials. JAMA. 2002;288(3):358-362.

63. Singh JP, Grann M, Lichtenstein P, Langstrom N, Fazel S. A novel approach to determining violence risk in schizophrenia: developing a stepped strategy in 13,806 discharged patients. PLoS One. 2012;7(2): e3 1727 .
Patient Preference and Adherence

\section{Publish your work in this journal}

Patient Preference and Adherence is an international, peer-reviewed, open access journal that focuses on the growing importance of patient preference and adherence throughout the therapeutic continuum. Patient satisfaction, acceptability, quality of life, compliance, persistence and their role in developing new therapeutic modalities and compounds to optimize

\section{Dovepress}

clinical outcomes for existing disease states are major areas of interest for the journal. This journal has been accepted for indexing on PubMed Central. The manuscript management system is completely online and includes a very quick and fair peer-review system, which is all easy to use. Visit http://www. dovepress.com/testimonials.php to read real quotes from published authors. 